\title{
Erratum to: Can we do without mydriasis in multifocal ERG recordings?
}

\author{
Charlotte M. Poloschek • Michael Bach
}

Published online: 17 May 2013

(C) Springer-Verlag Berlin Heidelberg 2013

Erratum to: Doc Ophthalmol (2009) 118:121-127 DOI 10.1007/s10633-008-9146-5

The original article published in Volume 118, Issue 2 includes an error in Fig. 3. The correct version of the Fig. 3 is provided below.

The online version of the original article can be found under doi:10.1007/s10633-008-9146-5.

C. M. Poloschek $(\bowtie) \cdot$ M. Bach

Sektion Funktionelle Sehforschung,

Universitäts-Augenklinik, Killianstr. 5,

79106 Freiburg, Germany

e-mail: charlotte.poloschek@uniklinik-freiburg.de 

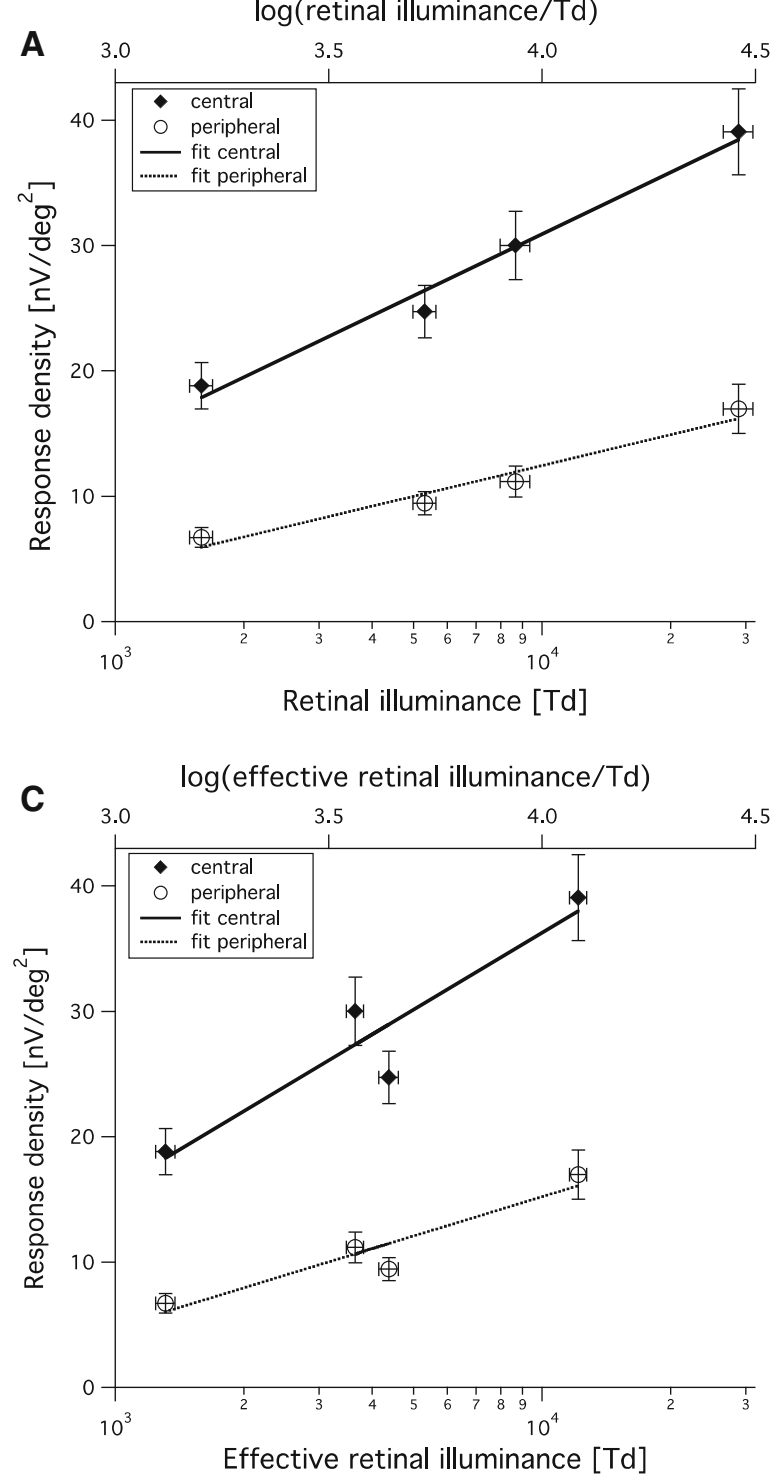

Fig. 3 Response densities in the four recording conditions as a function of retinal illuminance for the center and periphery (filled and empty circles, respectively). When the StilesCrawford effect is not corrected for (top), amplitudes increase (a) and peak times decrease (b) in the order of conditions LoNat,
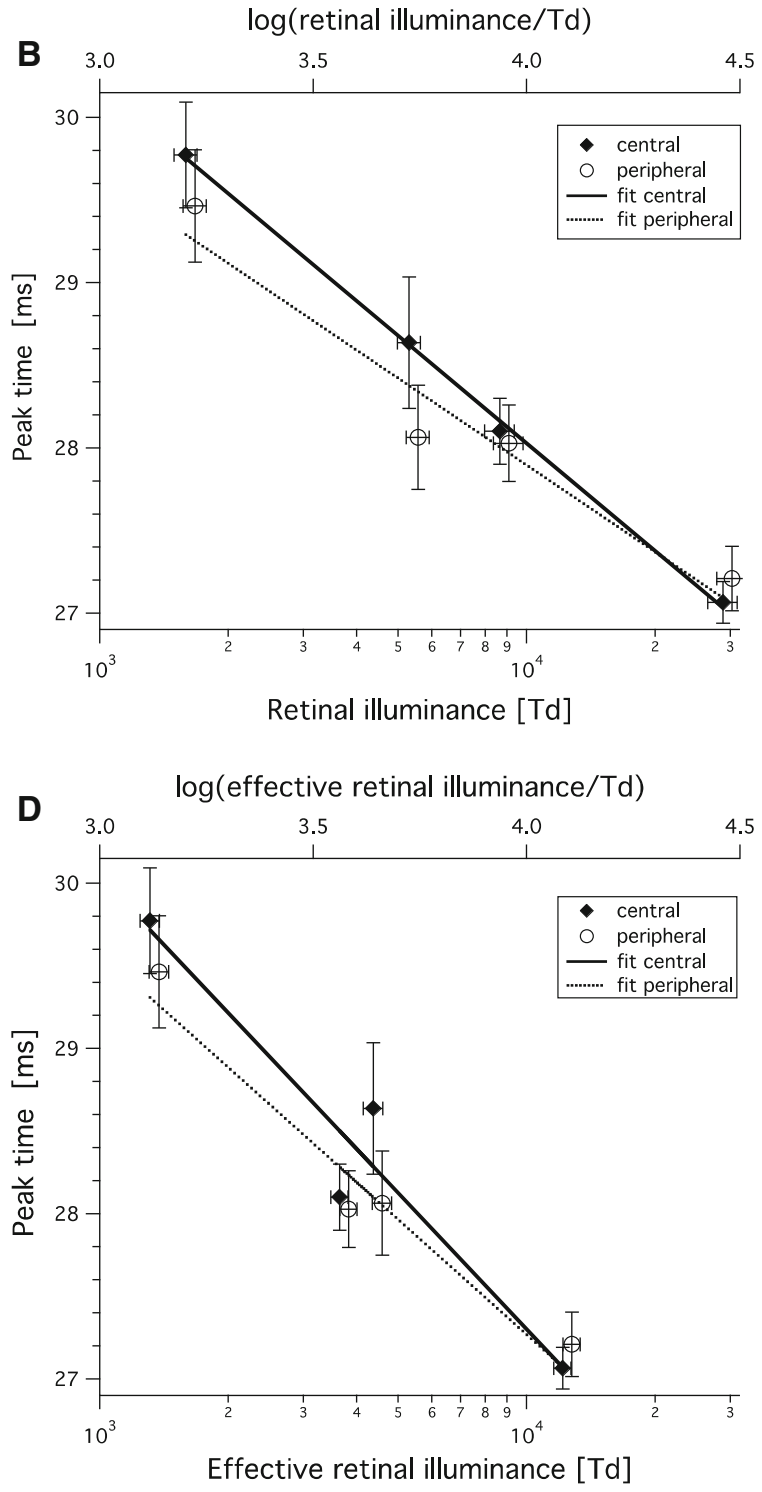

HiNat, LoDil, HiDil. When the Stiles-Crawford effect is fully corrected for (bottom, $\mathbf{c}, \mathbf{d}$ ), the effective retinal illuminances of the conditions HiNat and LoDil invert (without, naturally, any changes on the $y$-axes) 